Gut, 1962, 3, 327

\title{
17-Ketosteroid and 17-hydroxycorticosteroid excretion in patients with duodenal ulceration
}

\author{
A. G. GREEN AND C. N. PULVERTAFT
}

From the County Hospital, York

EDITORIAL SYNOPSIS The 24-hour excretion of 17-ketosteroids and 17-hydroxycorticosteroids has been estimated in a series of male duodenal ulcer subjects and compared with that of 56 normal male controls. It has been found that both 17-ketosteroid and 17-hydroxycorticosteroid excretion is less in ulcer subjects than in the control group; these differences are not large but in the case of 17-hydroxycorticosteroids they are statistically significant. For active ulcers (107 men) 17-hydroxycorticosteroid excretion is approximately $78 \%$ of normal and 17 -ketosteroid excretion $93 \%$ of normal; in the quiescent phase (50 men) the differences are rather larger, being respectively $71 \%$ and $86 \%$ of normal. This reduced excretion persists after operation in both the short term, six months after operation (53 men), and the long term, 10 years and more after gastric resection (39 men).

There have been a number of suggestions of a relationship between the endocrine system, in particular the adrenal cortex, and gastro-duodenal ulceration but there are few reported studies of steroid excretion in ulcer subjects.

In 1950 Sandweiss, Saltzstein, Scheinberg, and Parks, using 24-hour urine collections in 31 controls (16 men and 15 women) and 43 duodenal ulcers ( 31 men and 12 women), with an age distribution of 20 to 66 years, reported that both 11-oxycorticosteroid and 17-ketosteroid excretion is reduced in ulcer subjects. Hetenyi (1950) also mentions that 17-ketosteroid excretion is considerably diminished in the active phase of duodenal ulcer. On the other hand, Seymour Gray (1958) reported 17-hydroxycorticosteroid excretion to be normal in ulcer subjects and Sleisenger, Lewis, Lipkin, and Wierum (1958), using 24-hour urine collections in 32 controls and 48 patients with peptic ulcer (a mixed group of men and women with active and inactive gastric and duodenal ulcers of an age range 19 to 85 years), concluded that 17-hydroxycorticosteroid excretion remained within normal limits for both active and inactive ulcers.

The present study relates to the comparative 24-hour excretion of 17-ketosteroids and 17-hydroxycorticosteroids in groups of male duodenal ulcer subjects and a comparable group of normal men. In attempting any such comparison, it must be appreciated that there are many factors which influence excretion, e.g., sex, age, body mass, daily variation, and others, such as the effect of stress, which are difficult to assess; moreover, the normal range for both 17-ketosteroids and 17-hydroxycorticosteroids is considerable (Figs. 1a and b). It is, therefore, important that the methods used and the sex and age distribution of the subjects should be clearly defined.

\section{METHODS AND MATERIAL}

On account of the daily variation in excretion, it is desirable that comparisons should be based on three consecutive 24-hour urine collections but, in practice, this is difficult to achieve. It was found that both controls and patients were willing to cooperate as out-patients in a 24-hour collection if this was confined to a weekend, but attempts at collection during working days were highly inaccurate. Three-day samples, therefore, implied in-patient collection but we were unable to define a suitable control group amongst the hospital in-patient population. We have, therefore, used single 24-hour outpatient samples; this has an advantage because it permits collection under normal living conditions and avoids the varying stress factor of a period in hospital but it is open to criticism on the completeness of the sample. For this reason, we feel that comparisons can only be made on a group basis and that the groups should be reasonably large, i.e., 30 or more subjects.

Total 17-hydroxycorticosteroids were estimated by a modification of the method of Appleby, Gibson, Norymberski, and Stubbs (1955). A larger aliquot of urine was subjected to borohydride reduction followed by bismuthate oxidation. Acid hydrolysis and benzene 
TABLE I

NUMBER OF SUBJECTS AND AGE DISTRIBUTION

Age (yr.) Controls Duodenal Ulcers

\begin{tabular}{llll}
\hline Active & Quiescent & Late Gastrectomy & Six Months after Operation
\end{tabular}

\begin{tabular}{|c|c|c|c|c|c|}
\hline $\begin{array}{l}-19 \\
20-29 \\
30-39 \\
40-49 \\
50-59 \\
60-69 \\
70-75 \\
\text { Total No. } \\
\text { Mean Age }\end{array}$ & $\begin{array}{c}2 \\
7 \\
11 \\
17 \\
11 \\
8 \\
0 \\
56 \\
43.6\end{array}$ & $\begin{array}{r}1 \\
9 \\
29 \\
30 \\
28 \\
8 \\
2 \\
107 \\
44 \cdot 4\end{array}$ & $\begin{array}{c}0 \\
4 \\
10 \\
8 \\
17 \\
11 \\
0 \\
50 \\
48 \cdot 8\end{array}$ & $\begin{array}{c}0 \\
0 \\
2 \\
12 \\
21 \\
4 \\
0 \\
39 \\
51 \cdot 1\end{array}$ & $\begin{array}{c}1 \\
4 \\
6 \\
22 \\
16 \\
2 \\
2 \\
53 \\
45 \cdot 8\end{array}$ \\
\hline
\end{tabular}

'Late gastrectomy' implies 10 years or more after resection.

'Six months after operation' is a mixed group following partial gastrectomy, vagotomy and gastro-enterostomy or vagotomy and antrectomy.

extraction followed. After washing the extract and taking down to dryness a Zimmermann reaction was carried out on the residue under standard conditions.

17-Ketosteroids were estimated by a technique involving acid hydrolysis under reflux followed by ether extraction after making the hydrolysed urine alkaline. After washing the extract a Zimmermann reaction was carried out on an aliquot of the dried residue.

These methods have been described in detail by Green (1961).

The duodenal ulcer patients were divided into four distinct groups: 1 Patients in an active phase of ulceration; 2 patients in a quiescent phase. This is a composite group consisting of those patients who had an acute perforation at least two years previously and have been symptom-free for this period, and those in a symptom-free phase; 3 patients who had undergone partial gastrectomy at least 10 years before; 4 patients six months after operation, the operations being partial gastrectomy, vagotomy and gastromy-enterostomy, and vagotomy and antrectomy.

The control group was drawn from members of the hospital staff and from the practice of a general practitioner, the only criterion being that they should be normal, fit subjects, with no known history of gastroduodenal ulcer. The age distribution and numbers of these groups are shown in Table I.

\section{RESULTS}

The values for 17-ketosteroid and 17-hydroxycorticosteroid excretion in the 56 normal controls are shown in Figs. 1a and b. These results are comparable with other reported normals, such as those of Levell, Mitchell, Paine, and Jordan (1957). There is a considerable variation in normal excretion and in both instances it diminishes with increasing age.

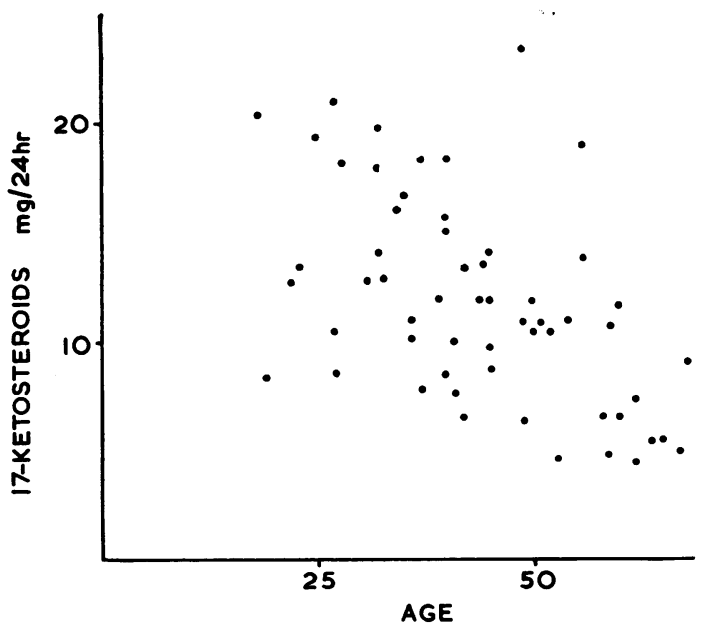

FIG. 1a. Excretion of 17-ketosteroids in 56 normal controls over 24 hours.

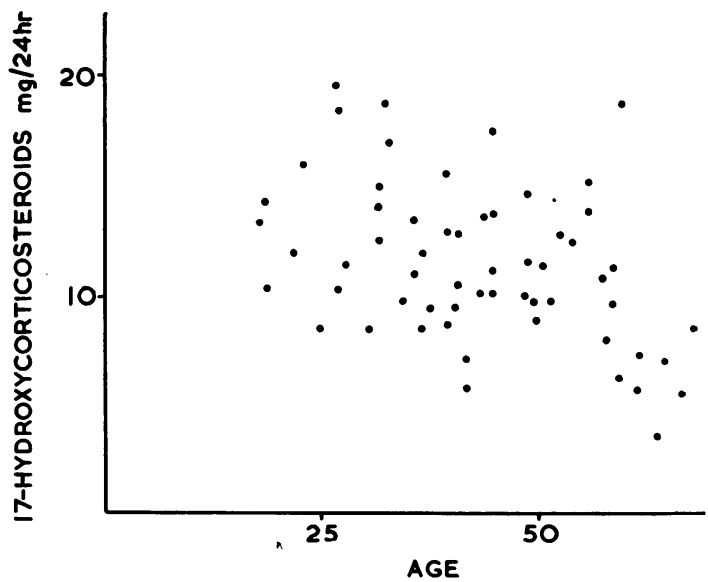

FIG. 1b. Excretion of 17-hydroxycorticosteroids in 56 normal controls over 24 hours. 


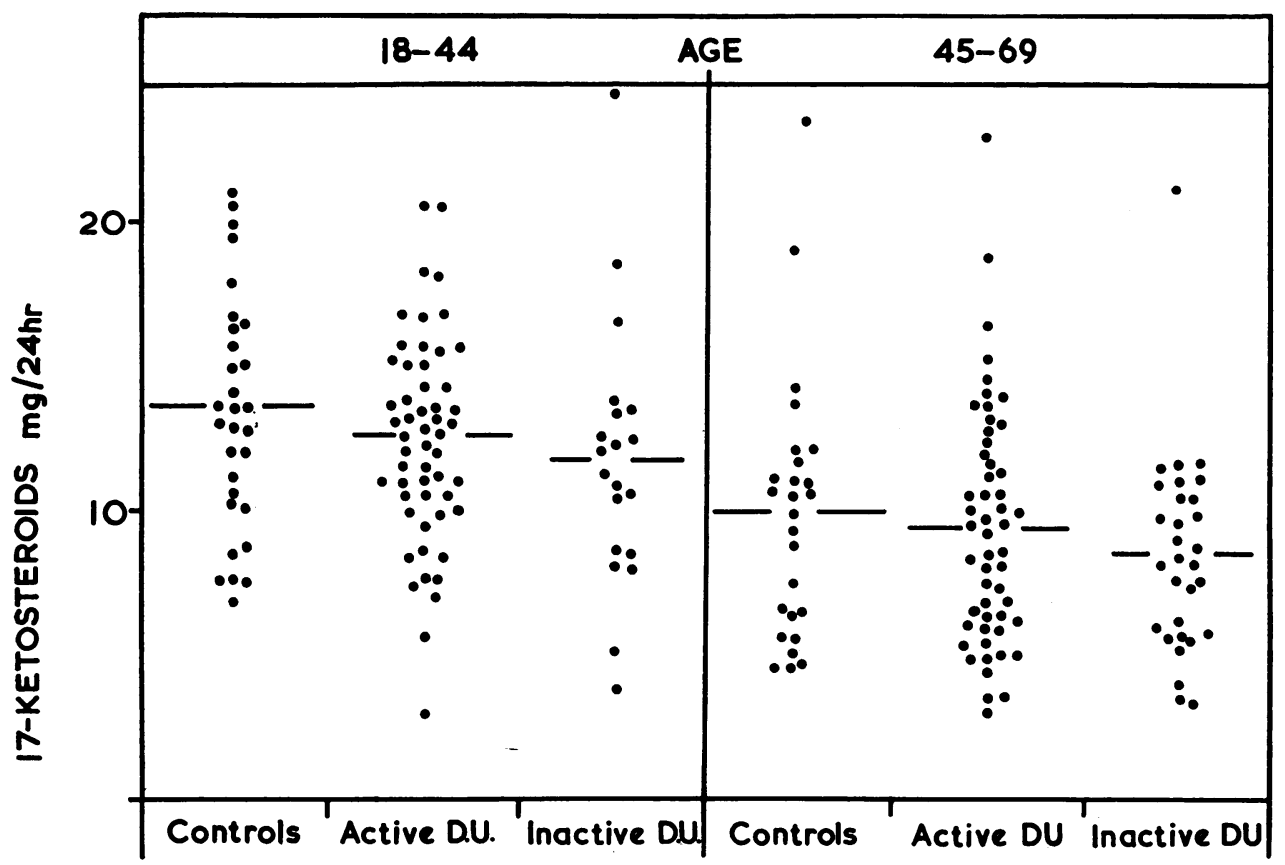

FIG. 2a. Comparative excretion of 17-ketosteroids in controls and patients with active and inactive duodenal ulcers, presented in two age groups. The transverse lines indicate the mean values.



FIG. 2b. Comparative excretion of 17-hydroxycorticosteroids in controls and patients with active and inactive duodenal ulcers, presented in two age groups. The transverse lines indicate the mean values. 
The comparative findings for controls and for patients with active and quiescent duodenal ulcers, divided into two age groups, up to 44 and 45 and over, are summarized in Figs. $2 a$ and $2 b$. In the case of 17-ketosteroids, there is little difference between the controls and ulcer subjects and even with 17-hydroxycorticosteroids there is a considerable overlap between the groups, more marked in patients with active than with quiescent ulcers. It will be noted that 17-hydroxycorticosteroid excretion in ulcer subjects tends to be in the lower half of the normal range but not pathologically low.

The mean excretion of each group is shown in Table II; the mean for both 17-ketosteroids and 17hydroxycorticosteroids for all ulcer groups is less than the controls. This is more marked for 17hydroxycorticosteroids than for 17-ketosteroids and for patients with quiescent than for those with active ulcers. The values for 17-hydroxycorticosteroids for the post-operative groups lie between the groups with active and with quiescent ulcer.

The question arises whether these differences are significant. The correlation coefficients and regression equations for the relationship between excretion and age for the three groups-controls, active, and quiescent duodenal ulcers-are set out in Table III. The regression coefficients on age are clearly similar in the three groups of subjects and statistical analysis shows that they are not significantly different from one another. The means of the observations, however, do differ appreciably. The differences between the means are highly significant for 17hydroxycorticosteroids between the controls and the patients with active ulcers $(P=0.001)$ and between the controls and the patients with quiescent ulcers $(P<0.001)$. For 17-ketosteroids the difference between the means of the observations is significant for the controls and for the patients with quiescent ulcers $(0.01<\mathrm{P}<0.02)$.

The regression lines are probably the clearest method of illustrating the effect of age on excretion and the relative values for controls and for subjects with active and quiescent ulcers at different ages, the reduced excretion for ulcer subjects being apparent at all ages (Figs. 3a and 3b). The differences are not large but are consistent, 17-hydroxycorticosteroid excretion in active ulcers being $77 \%, 78 \%, 79 \%$, and $80 \%$ of the control group at the ages of $30,40,50$, and 60 ; for quiescent ulcers the respective figures are $71 \%, 71 \%, 71 \%$, and $72 \%$.

17-Ketosteroids follow a similar pattern but are less pronounced, e.g., at the ages of $\mathbf{4 0}$ and $\mathbf{5 0}$ the excretions are $93 \%$ and $94 \%$ for active and $86 \%$ and $86 \%$ for quiescent ulcers of the control group.

In 11 ulcer subjects excretion was estimated during symptoms and in symptom-free periods; for 17ketosteroids, five gave a higher and six a lower result (mean $0.2 \mathrm{mg} . / 24$ hours higher) in the symptom-free period; for hydroxycorticosteroids, one was higher and 10 lower (mean $3.5 \mathrm{mg} . / 24$ hours lower) in the period of quiescence.

\section{DISCUSSION}

Tanner, Healy, Whitehouse, and Edgson (1959) showed that in healthy young men there is a significant relationship between 17-ketosteroid and 17ketogenic steroid excretion and body weight; it has been suggested that the ulcer subjects suffer from malnutrition and that this factor may explain the observed differences.

The influence of body mass on excretion was not

TABLE II

MEAN 24-HOUR 17-KETOSTEROID AND 17-HYDROXYCORTICOSTEROID EXCRETION IN CONTROLS AND DUODENAL ULCER GROUPS

17-Ketosteroid (mg./24 hour)

Controls

Duodenal ulcer (active)

Duodenal ulcer (quiescent)

Late gastrectomy

Six months after operation

11.9

11.9
10.9
9.8

$8 \cdot 6$
$9 \cdot 8$
17-Hydroxycorticosteroid (mg.124 hour)

$\begin{array}{rr}11 \cdot 3 & 18-68 \\ 8 \cdot 7 & 18-74 \\ 7 \cdot 4 & 26-69 \\ 7 \cdot 8 & 37-64 \\ 8 \cdot 0 & 19-64\end{array}$

TABLE III

CORRELATION COEFFICIENT AND REGRESSION EQUATIONS FOR RELATIONSHIP BETWEEN EXCRETION OF 17-KETOSTEROIDS AND 17-HYDROXYCORTICOSTEROIDS AND AGE

\begin{tabular}{|c|c|c|c|c|}
\hline & \multicolumn{2}{|l|}{ 17-Ketosteroid } & \multicolumn{2}{|l|}{ 17-Hydroxycorticosteroid } \\
\hline & Correlation Coefficient & Regression Equations & Correlation Coefficient & Regression Equations \\
\hline $\begin{array}{l}\text { Controls } \\
\text { Duodenal ulcer (active) } \\
\text { Duodenal ulcer (quiescent) }\end{array}$ & $\begin{array}{l}r=-0.514 \\
r=-0.458 \\
r=-0.469\end{array}$ & $\begin{array}{l}y=-0.186 x+19.972 \\
y=-0.158 x+17.964 \\
y=-0.154 x+16.906\end{array}$ & $\begin{array}{l}\mathbf{r}=-0.396 \\
\mathbf{r}=-0.259 \\
\mathbf{r}=-0.310\end{array}$ & $\begin{array}{l}y=-0.106 x+15.938 \\
y=-0.071 x+11.940 \\
y=-0.074 x+11.293\end{array}$ \\
\hline
\end{tabular}




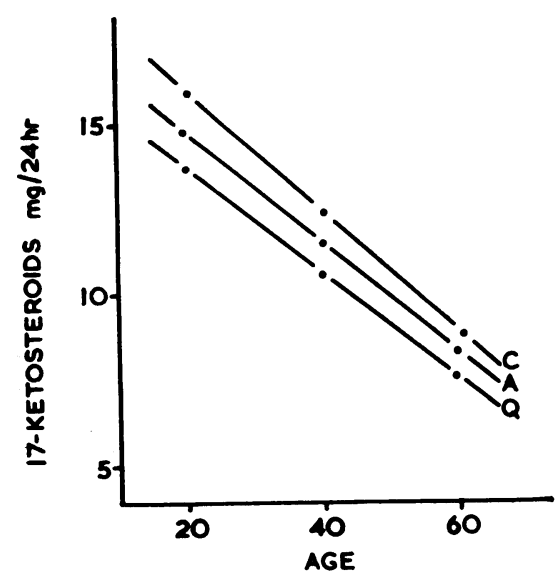

FIG. 3a. Regression lines for relationship between excretion of 17-ketosteroids and age for controls (C), active (A), and quiescent $(\mathrm{Q})$ duodenal ulcers.

fully appreciated in the earlier stages of this study and, therefore, the heights and weights of the control group were not recorded at the time of urine collection. These are, however, known for the majority of ulcer patients and, apart from the post-operative groups, they differ little from the expected normal weights (based on data published by the Institute of Actuaries); for instance, the patients with quiescent ulcers with the lowest mean 17-hydroxycorticosteroid excretion are, on average, within $2 \mathrm{lb}$. of the expected weight. On the other hand, those in the late postgastrectomy group, with a slightly higher mean 17hydroxycorticosteroid excretion, are well below weight, an average of 1 stone $5 \mathrm{lb}$. per patient.

The present data are insufficient to permit an accurate assessment, with due allowance for age distribution, of the relationship between body weight and steroid excretion but so far as it goes, it does suggest that within groups such does exist. This may be illustrated (Table IV) for the patients whose weight was recorded in the age group $\mathbf{4 0}$ to 59 years. Three ulcer groups-active ulcers, late gastrectomies, and quiescent ulcers-have each been separated into

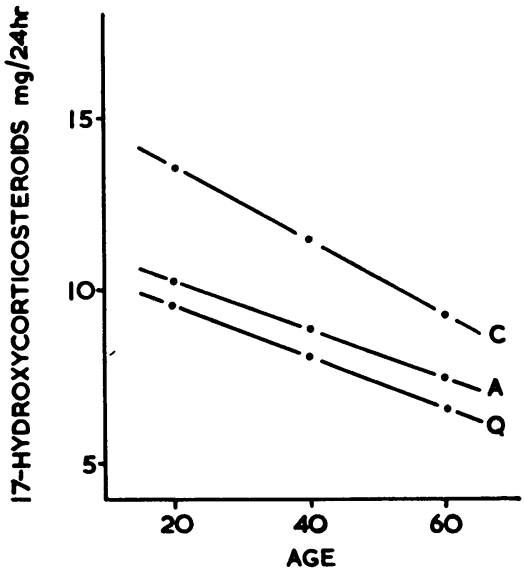

FIG. 3b. Regression lines for relationship between excretion of 17-hydroxycorticosteroids and age for controls (C), active (A), and quiescent (Q) duodenal ulcers.

three weight groups, namely, less than 9 stones $13 \mathrm{lb}$., 10 stones to 10 stones $13 \mathrm{lb}$., and 11 stones or more; although the numbers in each group are too small to draw positive conclusions, it would appear that excretion does increase with weight.

It is also possible that, for some reason, the collection was more complete in the controls than in the ulcer groups. This is an unlikely explanation but the possibility of error here warrants consideration. The excretion of 17-hydroxycorticosteroids in controls and in active and quiescent ulcers for large volumes of urine $(1,500 \mathrm{ml}$. and more) and small volumes $(1,499$ or less) is compared in Table $V$. The proportions of controls and patients with active ulcers with large and small volumes are very similar and it is reasonable to assume that collections were equally accurate. However, the mean excretion in controls is slightly greater with the larger volumes (11.7:10.9 mg./24 hours); this difference is more pronounced in the active ulcer group $(10 \cdot 1: 7 \cdot 3 \mathrm{mg}$./ 24 hours) but is not observed in the quiescent ulcer group. The reason for the fairly marked variation in the active ulcer group requires more detailed con-

TABLE IV

EXCRETION OF 17-HYDROXYCORTICOSTEROID (MG./24 HOUR) IN RELATION TO WEIGHT FOR AGE GROUP 40 TO 59

\begin{tabular}{|c|c|c|c|c|c|}
\hline & \multicolumn{3}{|l|}{ Weights } & \multicolumn{2}{|c|}{ Means for Group } \\
\hline & 9 st. $13 \mathrm{lb}$. & 10 st. to 10 st. $13 \mathrm{lb}$. & 11 stone & Age $(y r)$. & 17-Hydroxycorticosteroid \\
\hline $\begin{array}{l}\text { Active duodenal ulcer } \\
\text { Late gastrectomy } \\
\text { Quiescent duodenal ulcer }\end{array}$ & $\begin{array}{l}6 \cdot 7(13)^{1} \\
6 \cdot 6(14) \\
6 \cdot 0(8)\end{array}$ & $\begin{array}{l}6.9(18) \\
8.0(10) \\
7 \cdot 4(6)\end{array}$ & $\begin{array}{l}10.5(19) \\
9.0(6) \\
7.0(9\end{array}$ & $\begin{array}{l}48 \cdot 8 \\
50 \cdot 3 \\
50 \cdot 2\end{array}$ & $\begin{array}{l}8 \cdot 2 \\
7 \cdot 5 \\
6 \cdot 8\end{array}$ \\
\hline
\end{tabular}

'Figures in brackets indicate the number in each group. 
TABLE V

MEAN 24-HOUR 17-HYDROXYCORTICOSTEROID EXCRETION IN RELATION TO VOLUME OF URINE COLLECTED

\begin{tabular}{|c|c|c|c|c|}
\hline & \multicolumn{4}{|l|}{ Urinary Volume $(\mathrm{ml})}$. \\
\hline & \multicolumn{2}{|l|}{$<1,499$} & \multicolumn{2}{|l|}{$>1.500$} \\
\hline & Mean 17-Hydroxycorticosteroid & Mean Age & Mean 17-Hydroxycorticosteroid & Mean Age \\
\hline $\begin{array}{l}\text { Controls } \\
\text { Active duodenal ulcer } \\
\text { Quiescent duodenal ulcer }\end{array}$ & $\begin{array}{c}10.9 \mathrm{mg} \cdot(27)^{1} \\
7.3 \mathrm{mg} \cdot(51) \\
7.5 \mathrm{mg} .(25)\end{array}$ & $\begin{array}{l}42 \cdot 1 \\
43 \cdot 8 \\
45 \cdot 1\end{array}$ & $\begin{array}{r}11.7 \mathrm{mg} .(29) \\
10.1 \mathrm{mg} .(56) \\
7.3 \mathrm{mg} .(25)\end{array}$ & $\begin{array}{l}45 \cdot 2 \\
44 \cdot 7 \\
51 \cdot 4\end{array}$ \\
\hline
\end{tabular}

${ }^{1}$ Figures in brackets indicate number of patients.

sideration but suggests that excretion in patients with active duodenal ulcers varies with the volume of urine.

Another possible factor is a seasonal variation in steroid excretion. It is not clear from these studies if such exists or not; the value for 17-hydroxycorticosteroid for both controls and patients with active ulcer is lower for the summer months (June to August) than the winter (December to February) but the numbers collected in the summer are too small to be conclusive. In any case, the ulcer group and controls have been interspersed and proportional numbers of each have been collected in the various seasons of the year.

These findings suggest that steroid excretion, in particular for 17-hydroxycorticosteroids, is significantly lower in duodenal ulcer subjects; the difference is, however, small and might be better regarded as physiological rather than pathological. The fact that it is lower in the quiescent than in the active group and persists after operation suggests that it is inherent in the ulcer subject rather than a secondary effect of ulceration. The explanation of this finding is, however, by no means clear and the implication is debatable. Further studies are essential before proferring any hypothesis.

We are grateful to Dr. Richard Doll for the statistical analysis of the data, to Dr. Guy Balf and Dr. Euan Spink of Easingwold for their help in collecting normal controls; and to our colleagues Dr. D. Laing, Mr. J. H. Conyers, Mr. R. A. Hall, and Mr. J. K. Willson-Pepper for their help.

\section{REFERENCES}

Appleby, J. I., Gibson, G., Norymberski, J. K., and Stubbs, R. D. (1955). Biochem. J., 60, 453-460.

Gray, S. J. (1958). Proc. World Congr. Gastroenterology, Washington, 1958, Vol. 1, 396-404.

Green, A. G. (1961). M.Sc. thesis, Univ. of Durham.

Hetenyi, G. (1950). Schweiz. med. Wschr., 80, 1032-1033.

Levell, M. J., Mitchell, F. L., Paine, C. G., and Jordan, A. (1957). J. clin. Path., 10, $72-79$.

Sandweiss, D. J., Saltzstein, H. C., Scheinberg, S. R., and Parks, A. (1950). J. Amer. med. Ass., 144, 1436-1442.

Sleisenger, M. H., Lewis, C. M., Lipkin, M., and Wierum, C. (1958). Amer. J. Med., 25, 395-400.

Tanner, J. M., Healy, M. J. R., Whitehouse, R. H., and Edgson, A. C. (1959). J. Endocr., 19, 87-101. 